\title{
BMJ Open Improving physical functional and quality of life in older adults with multiple sclerosis via a DVD-delivered exercise intervention: a study protocol
}

\author{
Thomas R Wójcicki, ${ }^{1}$ Sarah A Roberts, ${ }^{2}$ Yvonne C Learmonth, ${ }^{2}$ \\ Elizabeth A Hubbard, ${ }^{2}$ Dominque Kinnett-Hopkins, ${ }^{2}$ Robert W Motl, ${ }^{2}$ \\ Edward McAuley ${ }^{2}$
}

To cite: Wójcicki TR, Roberts SA, Learmonth YC, et al. Improving physical functional and quality of life in older adults with multiple sclerosis via a DVD-delivered exercise intervention: a study protocol. BMJ Open 2014;4: e006250. doi:10.1136/ bmjopen-2014-006250

- Prepublication history for this paper is available online. To view these files please visit the journal online (http://dx.doi.org/10.1136/ bmjopen-2014-006250).

Received 28 July 2014 Revised 24 October 2014 Accepted 7 November 2014

CrossMark

\footnotetext{
${ }^{1}$ Exercise Science Department, Bellarmine University, Louisville, Kentucky, USA

${ }^{2}$ Department of Kinesiology \& Community Health, University of Illinois at Urbana-Champaign, Urbana, Illinois, USA
}

Correspondence to Dr Edward McAuley; emcauley@illinois.edu

\section{ABSTRACT}

Introduction: There is a need to identify innovative, low-cost and broad-reaching strategies for promoting exercise and improving physical function in older adults with multiple sclerosis (MS).

Methods and analysis: This randomised controlled pilot trial will test the efficacy of a 6-month, DVDdelivered exercise intervention to improve functional performance and quality of life in older adults with MS. Participants will be randomised either into a DVDdelivered exercise condition or an attentional control condition. This novel approach to programme delivery provides participants with detailed exercise instructions which are presented in a progressive manner and includes a variety of modifications to better meet varying levels of physical abilities. The targeted exercises focus on three critical elements of functional fitness: flexibility, strength and balance. It is hypothesised that participants who are randomised to the exercise DVD condition will demonstrate improvements in physical function compared with participants assigned to the attentional control condition. Data analysis will include a 2 (condition) $\times 2$ (time) mixed factor analysis of variance (ANOVA) that follows intent-to-treat principles, as well as an examination of effect sizes. Participants will take part in qualitative interviews about perspectives on physical activity and programme participation.

Ethics and dissemination: The study protocol was approved by a university institutional review board and registered with a federal database. Participants will be asked to read and sign a detailed informed consent document and will be required to provide a physician's approval to participate in the study. The exercise DVDs include an overview of safety-related concerns and recommendations relative to exercise participation, as well as detailed instructions highlighting the proper execution of each exercise presented on screen. Following completion of this trial, data will be immediately analysed and results will be presented at scientific meetings and published in scholarly journals. Trial registration number: Clinical Trials NCT01993095.

\section{Strengths and limitations of this study}

Innovative, broad-reaching design for delivery of a physical activity programme to older adults with multiple sclerosis (MS) via DVD.

- Progressive 6-month exercise programme with built-in modifications to meet varying physical abilities.

- Efficacy of using a DVD-delivered exercise intervention to older adults with MS to improve physical function and quality of life remains to be determined.

\section{INTRODUCTION}

The older adult population is in the midst of unprecedented growth and is projected to make-up $21 \%$ of the US population by 2040. ${ }^{1}$ This dramatic change in the demographic landscape presents significant medical, societal and economic challenges, ${ }^{2}$ particularly as older age is generally accompanied by reductions in physical function and increased levels of disability. ${ }^{3-5}$ These seemingly inherent consequences of aging can often be further exacerbated by the onset and/or progression of chronic disabling diseases, such as multiple sclerosis (MS). The prevalence of MS, a progressive neurodegenerative disease that affects the central nervous system, ${ }^{6}$ is estimated to be 2.3 million people worldwide, with more than 400000 cases in the USA alone, ${ }^{7}$ and $45 \%$ are aged 55 years and older. ${ }^{8}$ Even with variations in the pathological manifestations of MS, some of the most common symptoms and impairments mirror those that are characteristically associated with aging, such as reduced strength, difficulties with balance, mobility, and coordination, frequent fatigue, cognitive dysfunction, and compromised 
quality of life (QOL). ${ }^{9-11}$ Unfortunately, there is a dearth of research examining these outcomes in older adults with MS. ${ }^{12} 13$

Physical inactivity among individuals with $\mathrm{MS}^{14}$ may exacerbate problems associated with this chronic condition. Physical activity participation, by comparison, can confer a protective and potential restorative effect on functional limitations and disability in older adults with $\mathrm{MS}^{15-17}$ and may also have a protective effect on the rate of disease progression. ${ }^{18}$ Thus, it is imperative to establish methods to increase levels of physical activity engagement in the MS population. Although a number of exercise interventions have been safely and successfully implemented for more general or younger segments of the MS population, ${ }^{19-21}$ to the best of our knowledge, there have been no interventions designed for and specifically targeting older adults with MS. Additionally, the majority of MS-specific exercise interventions tend to be supervised, centre-based (eg, fitness centres, university laboratories, medical settings, etc) programmes, which can provide challenges to participation, in terms of accessibility and ultimately resulting in limited generalisability. ${ }^{22}$ Additionally, centre-based programmes have limited reach, can be difficult to implement, and are often resource intensive (eg, costs, time, staff, etc). There is a need to identify innovative, low-cost and broad-reaching strategies specifically aimed at improving physical function and, as a result, delaying (or at the very least minimising) the progression of functional limitations and disability in older adults with MS.

Targeted exercise training via DVD may be one contemporary approach in achieving this goal. Commercial revenue for exercise DVDs exceeded \$260 million in the past 5 years and demand remains high, especially among older adults. ${ }^{23}$ The efficacy of delivering such programmes via DVD to improve physical function in older adults living with chronic disease remains to be determined. A recent study examined the efficacy of a progressive, home-based, DVD-delivered exercise programme (ie, FlexToBa) focusing on improving flexibility, strength and balance in low-active community-dwelling older adults $(\mathrm{N}=307) .{ }^{24}$ Participants randomised to the exercise DVD condition showed significant improvements on the Short Physical Performance Battery (SPPB),${ }^{25}$ as well as on measures of strength and upper and lower extremity flexibility. Additionally, this novel DVD-delivered intervention appears to be safe and well tolerated, with participants reporting high levels of satisfaction and a respectable rate of adherence, particularly for a home-based exercise programme ( $75 \%$ across the 6 months). ${ }^{24}$ It should be noted, however, that while participants experienced gains in measures of functional performance, the study sample still had arguably high levels of function at baseline. Older adults with MS would be expected to have more compromised levels of function than this healthier and higher functioning sample.

\section{METHODS}

\section{Study design and primary objectives}

The design is a two-arm, 6-month randomised controlled trial with participants randomised to either the FlexToBa DVD (ie, exercise) condition or a Healthy Aging DVD (ie, attentional control) condition (see figure 1). Stratified randomisation by age and sex will be conducted to ensure similar demographic characteristics between the two conditions and to control for the potential influence of these covariates on study outcomes. The objective of this pilot trial is to test the efficacy of a DVD-delivered exercise intervention designed to enhance physical function (eg, mobility, strength and flexibility) in older adults with MS. Although this programme was initially developed for low-active, community-dwelling older adults, ${ }^{24}$ we believe that it may be appropriate for individuals with MS, as well, particularly given their limited engagement in physical activity and high degree of functional limitations. Primary outcomes include physical function performance and QOL. We hypothesise that older adults with MS randomised to the exercise DVD condition will demonstrate improvements in markers of physical function (ie, flexibility, strength and balance), physical activity and QOL compared with participants assigned to the attentional control condition. Effect sizes generated from this pilot trial will assist in powering a future definitive trial. Additionally, qualitative interviews will be conducted post-intervention to further assess participants' attitudes towards physical activity and experience in the intervention.

\section{Participants}

We will recruit 50 persons with MS who are aged 50 years and older throughout the state of Illinois and from western Indiana. This sample size was selected primarily due to the narrow time frame of the funding period, as well as to generate effect sizes for the primary outcomes.

\section{Recruitment strategies and procedures}

Recruitment materials will highlight the opportunity to participate in a free, professionally developed, in-home physical activity programme designed to enhance elements of physical fitness that have implications for the successful maintenance of independent living in older adults with MS. The recruitment plan is to distribute study announcements through multiple avenues, such as contacting previous research participants with MS via phone, distributing flyers and brochures highlighting this research opportunity, sending programme information via MS-specific listsrvs, and posting web-based advertisements (eg, the website of the Greater Illinois chapter of the National Multiple Sclerosis Society). Study and recruitment information will also be distributed at various MS support meetings. Finally, we plan to utilise a large local hospital as a recruitment source. All ads will encourage interested participants to contact the research coordinator by phone or email for more detailed study information. A toll-free phone number will be available 


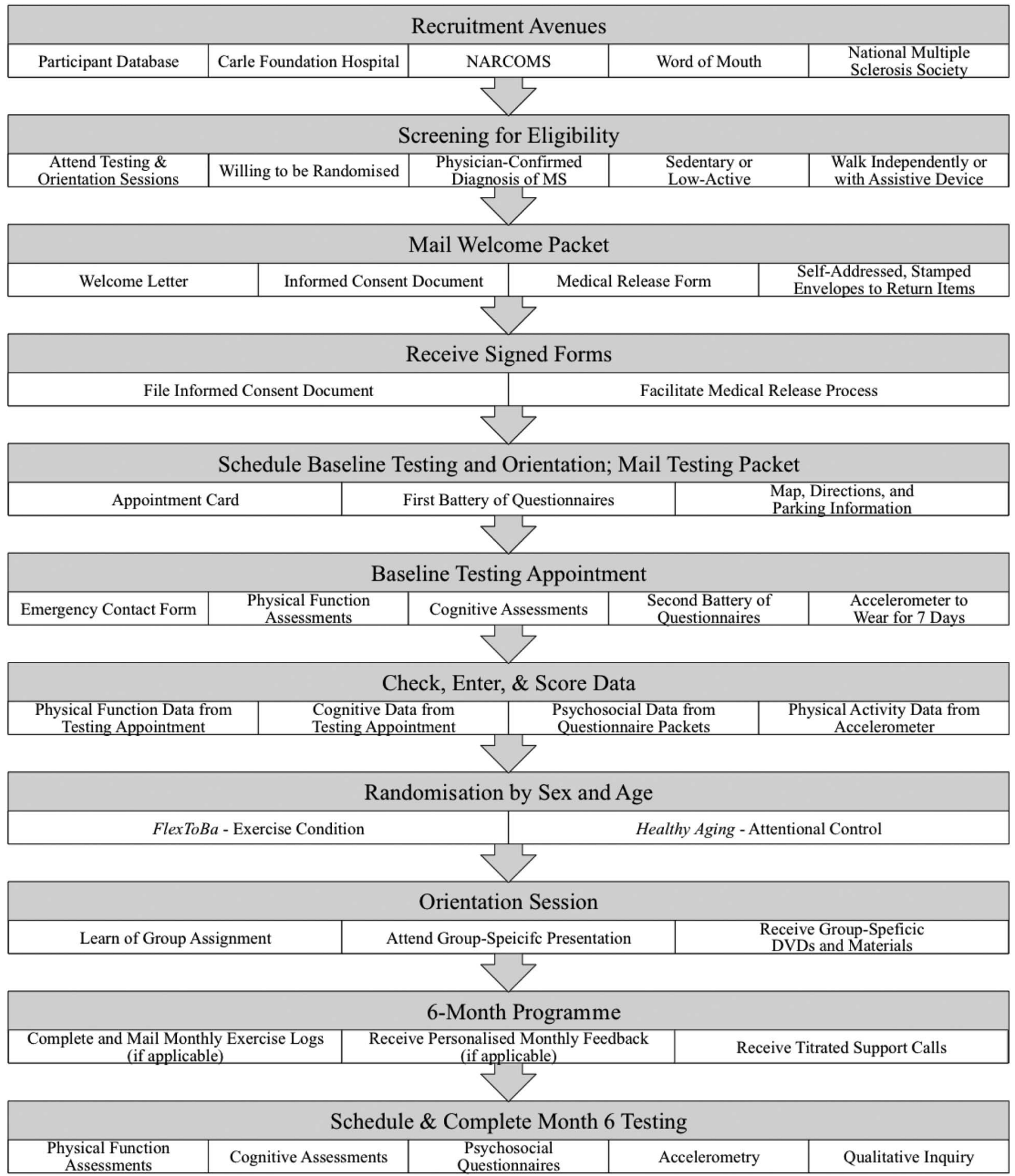

Figure 1 Study flow chart.

for people outside the local calling area and a prescreening telephone script will be used to determine eligibility prior to scheduling testing appointments.

\section{Eligibility criteria}

Inclusion criteria for participation will be: a definite diagnosis of MS that is confirmed in writing by the participant's neurologist or primary physician; being sedentary or physically inactive (ie, not regularly engaging in physical activities of $\geq 30 \mathrm{~min}$ on more than 2 days of the week during the past 6 months); aged 50 years or older; fluent in English; ambulatory with minimal assistance (ie, walk independently or with an assistive walking device); the provision of medical clearance for participation in a physical activity programme by participants' physicians; and an Expanded Disability Status Scale (EDSS) score of less than 6.5 (ie, constant bilateral assistance). ${ }^{26}$ The EDSS cut-off was selected for concerns 
with patient safety (ie, falls). Additionally, during the pre-screening phone call, cognitive impairment will be assessed by using the Modified Telephone Interview for Cognitive Status (ie, TICS-M) questionnaire to assess cognitive status. ${ }^{27}$ Potential subjects who score below 21 (of 39) on the TICS-M will be excluded from the trial. Potential participants who meet eligibility criteria and successfully pass the pre-screening will receive a letter inviting them to participate, a document requesting authorisation to contact their physician for clearance to participate, an informed consent document (including an additional copy for their personal records), and a self-addressed stamped envelope to return these documents. The study's research coordinator will be responsible for managing these mailings. On receipt of the signed documents, the research coordinator will file the informed consent form and contact the physician for the necessary clearance.

\section{Scheduling}

Following receipt of the signed informed consent document and obtaining medical clearance, participants will be scheduled (via phone) for a $2 \mathrm{~h}$ baseline testing visit at a university research laboratory. They will also be scheduled for a programme orientation meeting relative to the expectations of the programme and participant roles within their randomly assigned treatment condition. Finally, participants will be mailed an acceptance letter, a testing and orientation appointment sheet, a map with parking information and directions to the testing locale, and a battery of questionnaires to be completed at home and returned at the scheduled baseline testing session.

\section{Primary study outcomes}

Assessors who are blinded regarding treatment allocation will conduct assessments at baseline and again at 6 months, following programme termination. Details regarding the measures used for primary outcomes (ie, physical function performance and QOL), as well as a list of secondary outcome measures (eg, physical activity, cognition and psychosocial constructs), can be found in table 1 .

To strengthen our measurement approach, we will include measures that are used in the gerontology literature and complement them with measures used in the MS literature when possible. Tests of physical and cognitive function will be administered onsite in a research laboratory, psychosocial measures will be collected via a battery of questionnaires, and physical activity levels will be objectively assessed over a 7-day period. If needed, participants will be allowed to use assistive devices while performing walk-related assessments. A standardised testing script, which provides detailed assessment instructions, proposed demonstrations and safety-related recommendations, will be utilised to ensure uniformity of administration. Testing staff are experienced in the common functional assessments used in MS and will undergo extensive training prior to testing to ensure accuracy and consistency in data collection.

\section{Neurological disability}

All participants will undergo an initial neurological examination administered by a Neurostatus certified examiner using the EDSS score. ${ }^{26}$ The EDSS is the 'referent standard' measure of disability in clinical trials in MS. The EDSS is included for sample description only, not as an outcome of the intervention.

\section{Short Physical Performance Battery}

The SPPB will be used to assess lower extremity function via assessments of balance, mobility and leg strength. ${ }^{25}$ Participants will be instructed to complete a series of balance tests sequentially (ie, gradually increasing in terms of physical challenge). This is a three-part test in which each balancing position must be successfully completed prior to moving on to the next, more challenging task. Participants will first undergo the side-by-side stand test (ie, standing with the medial sides of their feet placed together), followed by the semitandem stand test (ie, standing while touching the medial side of the heel of one foot to the medial side of the big toe on the other), and finally the tandem stand test (ie, standing with the heel of one foot touching the tip of big toe on the other foot). Balance must be maintained for $10 \mathrm{~s}$ prior to proceeding to subsequent tests. Should a participant not successfully reach the $10 \mathrm{~s}$ mark(s), their testing for the balance portion of the SPPB is concluded. Testing staff will use stopwatches to evaluate and record the length of time each position (if applicable) is held.

The next component of the SPPB is the gait speed test. Participants will be encouraged to complete this task without an assistive walking device (eg, cane and walker); however, they will be permitted to use assistance should they feel unsafe or uncomfortable completing the walking task after being presented with testing instructions. Participants will be asked to approach a clearly marked, $4 \mathrm{~m}$ course where they will be instructed to walk briskly through the end of the course. This assessment will be conducted twice and the time taken to complete each walk will be recorded.

The final component of the SPPB is the two-part chair stand test that is designed to assess lower extremity strength. First, participants will be instructed to sit in a chair and then, when ready, stand from the seated position without the use of arms or an assistive device. Should this first task be completed successfully, the participant will be allowed to complete the subsequent repeated chair stand test. If a participant is unable to stand from the seated position, the test is complete and they will not move forward to the second portion of the test. Those who move on to the repeated chair stand test will be provided with the same instructions in terms of standing up from a seated position; however, for this particular part of the test, they will be challenged to 
Table 1 Primary study outcome measures*

\begin{tabular}{|c|c|c|c|c|c|}
\hline Assessment tool & Outcome & Measures/dimensions & Score & Interpretation & Source \\
\hline $\begin{array}{l}\text { Short Physical } \\
\text { Performance Battery }\end{array}$ & $\begin{array}{l}\text { Lower } \\
\text { extremity } \\
\text { function }\end{array}$ & $\begin{array}{l}\text { Balance tests, gait speed } \\
\text { test, chair stand test }\end{array}$ & $0-16$ & $\begin{array}{l}\text { Higher score=greater } \\
\text { function }\end{array}$ & $\begin{array}{l}\text { Guralnik } \\
\text { et } a \text { R }^{5}\end{array}$ \\
\hline \multirow[t]{4}{*}{ Senior Fitness Test } & $\begin{array}{l}\text { Walking } \\
\text { endurance }\end{array}$ & 6 min walk & Distance (yards) & $\begin{array}{l}\text { Longer } \\
\text { distance=better } \\
\text { endurance }\end{array}$ & $\begin{array}{l}\text { Rikli and } \\
\text { Jones }^{28}\end{array}$ \\
\hline & $\begin{array}{l}\text { Upper body } \\
\text { strength }\end{array}$ & $30 \mathrm{~s}$ arm curl & $\begin{array}{l}\text { Number of } \\
\text { repetitions }\end{array}$ & $\begin{array}{l}\text { Higher } \\
\text { number=greater } \\
\text { strength }\end{array}$ & \\
\hline & $\begin{array}{l}\text { Upper body } \\
\text { flexibility }\end{array}$ & Back scratch & $\begin{array}{l}\text { Distance } \\
\text { ( } \pm \text { inches })\end{array}$ & $\begin{array}{l}\text { Negative } \\
\text { score=greater } \\
\text { flexibility }\end{array}$ & \\
\hline & $\begin{array}{l}\text { Lower body } \\
\text { flexibility }\end{array}$ & Chair sit-and-reach & $\begin{array}{l}\text { Distance } \\
\text { ( } \pm \text { inches })\end{array}$ & $\begin{array}{l}\text { Negative } \\
\text { score=greater } \\
\text { flexibility }\end{array}$ & \\
\hline $\begin{array}{l}\text { Multiple Sclerosis } \\
\text { Functional Composite }\end{array}$ & $\begin{array}{l}\text { Mobility/gait } \\
\text { speed }\end{array}$ & Timed 25-foot walk & Time (s) & $\begin{array}{l}\text { Lower time=better } \\
\text { mobility }\end{array}$ & Cutter et $a{ }^{29}$ \\
\hline $\begin{array}{l}\text { Hand-Held } \\
\text { Dynamometer }\end{array}$ & Grip strength & Right and left hand grip & $\begin{array}{l}\text { Force } \\
\left(\text { pounds/inch }{ }^{2}\right)\end{array}$ & $\begin{array}{l}\text { Higher value=greater } \\
\text { grip strength }\end{array}$ & Bohannon $^{30}$ \\
\hline One Leg Stand & Balance & Right and left Leg stand & $0-30 \mathrm{~s}$ & $\begin{array}{l}\text { Higher time=greater } \\
\text { balance }\end{array}$ & $\begin{array}{l}\text { Bohannon } \\
\text { et } a \beta^{11}\end{array}$ \\
\hline $\begin{array}{l}\text { Leeds Multiple } \\
\text { Sclerosis Quality of } \\
\text { Life Scale }\end{array}$ & $\begin{array}{l}\text { Quality of life } \\
\text { (QOL) }\end{array}$ & Disease-specific QOL & $1-8$ & $\begin{array}{l}\text { Higher } \\
\text { value=improved QOL }\end{array}$ & Ford et $a{ }^{\beta 2}$ \\
\hline $\begin{array}{l}\text { Multiple Sclerosis } \\
\text { Impact Scale }\end{array}$ & QOL & $\begin{array}{l}\text { Physical and } \\
\text { psychological } \\
\text { health-related QOL }\end{array}$ & $1-5$ & $\begin{array}{l}\text { Lower } \\
\text { value=improved QOL }\end{array}$ & Hobart et $a 1^{\beta 3}$ \\
\hline $\begin{array}{l}\text { Satisfaction with Life } \\
\text { Scale }\end{array}$ & QOL & Global QOL & $1-5$ & $\begin{array}{l}\text { Higher } \\
\text { value=improved QOL }\end{array}$ & Diener et $a \beta^{34}$ \\
\hline \multicolumn{6}{|c|}{$\begin{array}{l}\text { *Secondary measures include: accelerometry (Actigraph, Pensacola, Florida, USA; Models GT1M or GT3X); body mass index; Brief } \\
\text { International Cognitive Assessment for Multiple Sclerosis; }{ }^{35} \text { Exercise Goal-Setting Scale and Exercise Planning and Scheduling Scale; }{ }^{36} \\
\text { Exercise Self-Efficacy Scale }{ }^{37} \text { Fatigue Severity Scale; }{ }^{38} \text { Frequency of Forgetting Scale; }{ }^{39} \text { Gait Efficacy Scale; }{ }^{40} \text { Godin Leisure-Time Exercise } \\
\text { Questionnaire; }{ }^{41} \text { Hospital Anxiety and Depression Scale; }{ }^{42} \text { Abbreviated Late-Life Function and Disability Instrument; }{ }^{43} \text { Lifestyle Self-Efficacy } \\
\text { Scale; }{ }^{44} \text { Multidimensional Outcome Expectations for Exercise Scale; }{ }^{45} \text { Multiple Sclerosis Walking Scale-12; }{ }^{46} \text { Physical Self-Perception } \\
\text { Profile; } ;{ }^{47} \text { Short-Form McGill Pain Questionnaire; }{ }^{48} \text { Self-Efficacy for Walking Scale-Duration; }{ }^{49} \text { Sitting-Time Questionnaire; }{ }^{50} \text { UCLA } \\
\text { Loneliness Scale. }{ }^{51}\end{array}$} \\
\hline
\end{tabular}

complete five chair stand movements in a row within $60 \mathrm{~s}$. Testing staff will monitor time with a stopwatch and will record the number of successful repetitions (up to five) performed. Scores from each of these assessments will be summed together to create a composite score indicative of lower extremity function.

\section{Senior Fitness Test}

Selected components of the Senior Fitness Test ${ }^{28}$ will be used to assess other elements of physical function not included in the SPPB. First, they will complete a $6 \mathrm{~min}$ walk to assess walking endurance. A walking course will be set-up for the participant, where they will be instructed to walk as quickly yet safely for six continuous minutes with the goal of covering as much ground as possible. Time will be kept with a stopwatch and the total distance walked will be measured via a distance wheel. Testing staff will follow the participant from behind, as to not influence the chosen walking speed, while pushing a distance wheel along the walked course.
Second, a $30 \mathrm{~s}$ arm curl test will be conducted to assess upper-body strength. During this task, participants will be asked to sit near the side of a chair while holding a dumbbell and completing as many arms curls as possible within $30 \mathrm{~s}$. Females will be provided with a 5-pound weight for this task, while males will be asked to use an 8-pound weight. Should participants be unable to hold onto the dumbbell, weight-matched wrist weights will be provided as an alternative. Again, staff will use a stopwatch to monitor the time and will count, tally, and record the number of repetitions performed.

Next, upper-body flexibility will be assessed using the back-scratch test. Participants will first be instructed to take one hand and place it over the same-side shoulder with their palm facing down, fingers extended, and elbow pointed up. Participants will then reach down the middle of their back as far as they can. Once in place, they will be asked to place their remaining hand behind their back with the palm facing outward, with the goal of reaching up as far as they can to touch or overlap their extended middle fingers. As soon as the participant is in position, 
the tester will measure the distance between or overlapped by the two middle fingers with a ruler and record the reading.

And finally, the chair sit-and-reach test will be used to measure lower body flexibility. For this assessment participants will be instructed to sit near the front end of a chair while bending one leg, with feet flat on the floor, and extending the other, with only the heel touching the floor and toes pointed up towards the ceiling. The hands should then be set so that one is on top of the other with the tips of the middle fingers perfectly aligned. When in position, the participant will be told to reach as far forward towards their toes on the extended leg as they possibly can. The distance between the tip of their middle fingers and the tip of their shoe on the extended leg will be measured with a ruler and recorded.

\section{Timed 25-foot walk}

The timed 25-foot walk component of the Multiple Sclerosis Functional Composite will be used to assess participant mobility and gait-speed. ${ }^{29}$ Two trials will be conducted along a marked course and assistive devices will be allowed during this task, if needed. The time used to complete these two trials will be monitored using a stopwatch.

\section{Grip strength}

A hand-held dynamometer (Jamar-Hydraulic Hand Dynamometer, Sammons Preston Rolyan, Bolingbrook, Illinois 60440, USA) will be used to measure grip strength. ${ }^{30}$ Assessments will be conducted twice on each hand in an alternating fashion. Participants will be asked to keep the arm being tested at a $90^{\circ}$ angle against the side of their body. The tester will then place the dynamometer in the participant's hand and then ask the participant to squeeze the device as hard as they can for at least $3 \mathrm{~s}$. The force generated will be displayed on the dial of the dynamometer and will be immediately recorded prior to moving on to the other hand.

\section{One leg stand}

Balance will be assessed using a one leg stand test. ${ }^{31}$ This assessment measures how long the participant can hold their balance on each of their legs for up to $30 \mathrm{~s}$. Participants will be given one attempt on each leg and the tester will monitor the passing time with a stopwatch. Time will be recorded for the full $30 \mathrm{~s}$ unless the participants loses balance before time runs out (eg, hops, drops their raised foot to the floor).

\section{Quality of life}

The unidimensional, 8-item Leeds Multiple Sclerosis Quality of Life Scale will be used as a disease-specific measure of overall QOL. ${ }^{32}$ An example item is: 'I have felt happy about the future.' The scores range between 8 and 32, with lower scores representing better QOL. This scale has good internal consistency, test-retest reliability, evidence of score validity, and virtually no floor or ceiling effects. ${ }^{32}$ As an additional MS-specific measure, the 29-item Multiple Sclerosis Impact Scale will be used to assess the physical (20 items) and psychological components (9 items) of health-related QOL in persons with MS. ${ }^{33}$ An example item from the physical scale is: "In the past two weeks, how much have you been bothered by problems with balance?" An example item from the psychological scale is: "In the past two weeks, how much have you been bothered by feeling depressed?" Scores range between 0 and 100, with lower values representing greater health-related QOL. There is evidence for the reliability and validity of the MSIS-29 in samples of individuals with MS. ${ }^{52}$ Finally, the Satisfaction with Life Scale will be used as a global measure of QOL. ${ }^{34}$ This five-item, unidimensional scale asks participants to rate statements, such as 'I am satisfied with my life,' on a seven-point Likert scale. The scores can range between 7 and 35, with higher scores representing higher QOL. This measure is commonly used in psychosocial research and has good internal consistency, testretest reliability, and evidence of score validity. ${ }^{53}$

\section{Qualitative inquiry}

As part of the mixed methods research design all participants will be asked to participate in a semistructured one-to-one qualitative interview. Interviews will be undertaken on the final day of testing by the same assessor who completed the quantitative assessments. A semistructured interview script will be followed to ensure consistency. Interviewers will receive training from an experienced qualitative researcher in MS. The interviews will establish data on three primary areas: (1) the participant's views on one's daily activity practices (eg, "To help me better understand, can you tell me what you think of as physical activity?"); (2) the perceived consequences from taking part in the study (eg, "Were there any problems or non-beneficial experiences you could tell me about from following the program?") and (3) participants' views on general participation in the study and future plans (eg, "Overall, thinking about the entire program, what factor do you think was the most important?"). The data will be recorded, transcribed and analysed using a spiral approach ${ }^{54}$ whereby the researchers will move through a series of analytical circles which involve reading, memoing the data (ie, making notes in the transcriptions), describing, classifying and categorising the data into codes and themes in order to interpret and present the qualitative data. The qualitative data will be important for: explaining physical activity behaviours in older adults with MS, establishing the perceived consequences of participation in our programme, and gathering feedback to refine future physical activity interventions for older people with MS.

\section{Secondary outcomes}

A battery of secondary outcomes including measures of physical activity, cognition, functional limitations and pain will be assessed pre-intervention and post- 
intervention. The complete list of secondary outcomes is shown in table 1.

\section{Testing appointments}

All testing sessions, at both time points, will be conducted and supervised by individuals who are cardiopulmonary resuscitation (CPR) certified and have undergone extensive training to minimise the risk to participants. The research team responsible for administering the tests will be blinded regarding participants' treatment allocation. Next, participants will complete a series of clinical, functional and cognitive tests. The order of these assessments will be predetermined and standardised. Furthermore, participants will be provided with periods of rest throughout the testing session to help minimise potential fatigue that may result from participation in the functional fitness tests. Specifically, participants will complete the 25-foot walk first, followed by $3 \mathrm{~min}$ of rest before completing the $6 \mathrm{~min}$ walk. Subsequent functional assessments will be followed by additional breaks and participants will be encouraged to request additional periods of rest should they need it.

Finally, prior to departing from their baseline appointment, participants will receive an initialised accelerometer to objectively measure physical activity levels along with a corresponding wear-time log. Research staff will provide verbal and written instructions, as well as a selfaddressed, stamped envelope for the return of the accelerometer and wear-time log via the USA Postal Service. Participants will be instructed to wear the accelerometer for full 7 days before mailing the device back to the laboratory.

\section{Interventions}

The intervention was previously tested among older adults without MS and has been described elsewhere. ${ }^{24}$ The intervention group will receive basic exercise equipment (ie, resistance bands, yoga mat and exercise logs) and a total of three DVDs: one orientation disc and two discs containing six progressive exercise sessions. The orientation DVD will include a brief overview of the exercise programme, and a discussion of, and focus on, the importance of strength, balance and flexibility exercises for the maintenance of physical function. This disc will also provide an introduction to the exercise leaders and models, deliver detailed information regarding the proper completion of the programme-specific exercise logs, and address safety-related concerns. The six exercise sessions presented within the other two DVDs are comprised of an orchestrated sequencing of progressions (ie, beginning with simpler, more basic movements, and then building on exercises learned to ultimately engage in more complex movements). Delivering the exercise programme in such a manner helps to ensure that new challenges are built on a previous foundation and to help minimise the risk of injury. Participants will be instructed to inform research staff of any adverse events that might occur as a result of participation. This information will be documented, reported to the Institutional Review Board, and discussed in future publications regarding study outcomes. Furthermore, each of the exercises presented within the DVDs will include two additional versions that vary in difficulty to make the exercises more attainable or challenging for individuals of varying functional capabilities and to further reduce the risk of injury.

Using the standing military press exercise as an example, the exercise leader will instruct participants to stand straight with their feet in a staggered position while placing the centre of an exercise band directly between the front foot and the floor. She will then instruct them to grab the handles of the bands and position their hands so that the palms face forward/ outward (ie, towards the direction of the TV for those doing the exercise at home). Next, participants will be told to form a 'goal post' type position with their arms (ie, elbows in line with shoulders and forearms perpendicular with the ground). From this starting position, participants will be told to extend their elbows and press/raise their hands straight up over their head in a slow and controlled manner and up to the point where their thumbs almost touch. They will then be instructed to slowly lower the band back to starting position to complete one repetition. To modify the military press, participants will be encouraged to use light hand weights as opposed to standing on an exercise band, as this will provide less resistance and greater range of motion. To make the exercise more challenging, participants will be instructed to stand with both feet evenly spaced on the band while performing the movement, which will considerably increase the level of resistance.

Participants in the FlexToBa group will be instructed to exercise with the DVDs on a regular basis (ie, every other day or at least three times per week) and to complete and mail in the exercise logs on a monthly basis via previously provided self-addressed stamped envelopes. These logs will be collected and entered by select, unblinded research personnel, who will also be responsible for generating and mailing personalised programme feedback to the corresponding participants for each of the six monthly exercise sessions. These detailed feedback forms will provide graphic progress reports for the most recently completed exercise session (ie, days exercised with the DVD, days of other exercises outside of the programme, average time spent exercising, and averages of programme-specific ratings of perceived exertion and enjoyment). The form will include some written feedback relative to performance and progress and will also provide constructive and motivational comments and suggestions. Moreover, participants in this condition will receive brief (ie, $<5 \mathrm{~min}$ ) support calls from select unblinded staff members in a titrated fashion (ie, twice a month during the first 2 months of the programme, and then once a month for the remainder of the programme). The purpose of these calls is to simply check in on participant progress and/or setbacks 
(ie, injury), answer any programme-specific questions or concerns, confirm receipt and provide an overview of their personalised monthly feedback, and to provide some advice regarding exercise participation (ie, an 'exercise tip').

Participants in the attentional control condition will receive a copy of Dr Andrew Weil's Healthy Aging DVD, which focuses on various elements of successful aging but is not in and of itself specific to exercise. Participants will be asked to watch this DVD at least once in its entirety. This group will also receive brief, titrated support calls from the research staff. These calls will fall in line with the support call schedule for the exercise condition and will include an overview of one of the Healthy Aging DVD topics (eg, the importance of proper nutrition, social support, etc) along with some advice related to that particular topic (ie, 'healthy aging tip').

\section{Post-intervention testing at month 6}

All assessments will be completed again at month 6 , following the full completion of the 6-month exercise programme. When participants are scheduled for follow-up testing sessions, they will be reminded of the testing location, invited to participate in the qualitative interviews, and reminded not to disclose their group allocation to the assessing research team. All testing will take place at the same location as baseline testing, and will be administered by blinded research staff. Testing procedures will mirror those presented at baseline. Following completion of the follow-up appointment, control participants will be given the exercise DVDs and accessories prior to leaving. Additionally, all participants who complete the programme and related assessments, regardless of treatment allocation, will receive a total of $\$ 175$ for their time and travel-related expenses.

\section{Data management}

The principal investigators will be responsible for overseeing data collection, entry and management. Questionnaire data will be checked immediately in the presence of the research participant if possible for clarity and completeness at the time of collection. For data provided by mail, follow-up telephone calls to clarify missing data will be made. If necessary, incomplete or ambiguous results will be corrected with follow-up telephone calls and/or additional appointments with research staff. Data obtained from the onsite testing sessions will be entered onto a scorecard as the tests are performed and scores made available. Physical activity data provided by the accelerometer will be downloaded and scored using MS-specific cut points ${ }^{55}$ to determine the amount of physical activity engagement at varying intensities. The corresponding accelerometer logs will be used to validate wear time.

\section{Data analysis}

The proposed data analysis will be a 2 (FlexToBa vs Healthy Aging condition) $\times 2$ (time) mixed factor analysis of variance (ANOVA) that follows intent-to-treat principles. Missing data will be handled via multiple imputation analysis. F-statistics will be decomposed using post hoc analyses including paired and independent samples t tests with a Dunn-Bonferroni correction of $\alpha$. Effect sizes for F-statistics and differences in mean scores will be expressed as partial $\eta^{2}$ and Cohen's d, respectively.

\section{ETHICS AND DISSEMINATION}

Additionally, the trial was registered with ClinicalTrials. gov (NCT01993095). Prior to study involvement, all participants who meet eligibility criteria will be presented with and asked to sign an informed consent document detailing the study's purpose, assessments and data collection, risks and benefits, privacy and rights, costs and remuneration, and contact information. The informed consent document also stresses the fact that participation in this project is entirely voluntary and that participants are free to withdraw from the study at any time without penalty. Furthermore, confidentiality is assured for all participants with regard to any personal responses and information provided throughout the trial. All data collected will be numerically coded and aggregated; therefore, no individual data will be identifiable. Results from this study will be presented at scientific meetings and published in scholarly journals.

\section{DISCUSSION}

The purpose of this randomised controlled pilot trial is to test the efficacy of a 6-month, home-based, DVDdelivered exercise programme physical function and QOL in older adults with MS. Given that this programme was found to be efficacious in a large sample of relatively healthy community-dwelling older adults, ${ }^{24}$ we hypothesise that older adults with MS who get assigned to the exercise condition will experience similar if not greater effects on the physical function. Persons with MS are typically less active than their healthy counterparts and generally suffer from a higher degree functional limitations and disabilities than other older adults without chronic conditions. If participants in the exercise condition of this trial experience maintenance or improvements in physical function as a result of programme engagement, it could lead to improvements in QOL and may ultimately have a considerable impact on public health, especially for those within the MS community. While the low levels of physical function among this sample may present some unique challenges in terms of adherence to and progress with the exercise programme, we believe that the progressive nature of the programme, along with built-in exercise modifications and routine support calls, should adequately assist in minimising attrition and enhancing engagement. However, future studies will be needed to determine the effectiveness of delivering such an exercise programme without the regular contact and support of a research team. Nevertheless, this innovative mode of programme 
delivery possesses the potential for broad-scale dissemination and should be well-received by those affected by chronic disabling diseases due to its progressive and modifiable nature.

Acknowledgements The authors express their appreciation to: Ruth Franklin Sosnoff, PhD, and Julia Balto, project coordinators; Bill Yauch of RiellyBoy Productions; Erica Urrego, FlexToBa DVD exercise leader; and Grant Henry, Lynda Matejkowski, Joyce O'Donnell, Bernard Puglisi, Paula Smith, and Peter Tan, FlexToBa DVD exercise models. The authors also extend their thanks to Andrew Weil, MD, for the generous contribution of the Healthy Aging DVDs.

Contributors TRW contributed to the conception and design of the study, led programme orientation sessions, assisted with the acquisition of data, and drafted and revised the manuscript. SAR led programme orientation sessions, assisted with the acquisition of data, and helped to draft and revise the manuscript. YCL assisted with the acquisition of data, designed and will conduct the qualitative assessments, and contributed to the writing and revision of the manuscript. EAH and DK-H assisted with the acquisition of data, were responsible for conducting onsite assessments and interviews, and helped to draft and revise the manuscript. RWM contributed to the conception and design of the study, assisted with the acquisition of data, and helped to draft and revise the manuscript. EM conceived the study, made substantial contributions to its design, and contributed to the drafting and revision of the manuscript. All authors read and approved the final version of the submitted manuscript.

Funding This project is supported by grant number IL0009 from the National Multiple Sclerosis Society.

Competing interests None.

Patient consent Obtained.

Ethics approval The study protocol was approved by the University of Illinois at Urbana-Champaign's Institutional Review Board (Urbana, Illinois, USA; Protocol No. 14163).

Provenance and peer review Not commissioned; externally peer reviewed.

Open Access This is an Open Access article distributed in accordance with the Creative Commons Attribution Non Commercial (CC BY-NC 4.0) license, which permits others to distribute, remix, adapt, build upon this work noncommercially, and license their derivative works on different terms, provided the original work is properly cited and the use is non-commercial. See: http:// creativecommons.org/licenses/by-nc/4.0/

\section{REFERENCES}

1. A profile of older Americans: 2012. Administration on Aging website. http://www.aoa.gov/AoARoot/Aging_Statistics/Profile/index.aspx (accessed 2 Jun 2014).

2. Knickman JR, Snell EK. The 2030 problem: caring for aging baby boomers. Health Serv Res 2002;37:849-84.

3. Freedman VA, Martin LG, Schoeni RF. Recent trends in disability and functioning among older adults in the United States: a systematic review. JAMA 2002;288:3137-46.

4. Fried LP, Guralnik JM. Disability in older adults: evidence regarding significance, etiology, and risk. J Am Geriatr Soc 1997;45:92-100.

5. Kaplan GA, Strawbridge WJ, Camacho T, et al. Factors associated with change in physical functioning in the elderly: a six-year prospective study. J Aging Health 1993;5:140-53.

6. Chaudhuri A. Multiple sclerosis is primarily a neurodegenerative disease. J Neural Transm 2013;120:1463-6.

7. MS prevalence. National Multiple Sclerosis Society. http://www. nationalmssociety.org/About-the-Society/MS-Prevalence (accessed 2 Jun 2014).

8. Minden SL, Marder WD, Harrold LN, et al., eds. Multiple sclerosis: a statistical portrait. A compendium of data on demographics, disability, and health services utilization in the United States. Cambridge, MA: Abt Associates, Inc, 1993.

9. Amato MP, Ponziani G, Rossi F, et al. Quality of life in multiple sclerosis: the impact of depression, fatigue and disability. Mult Scler 2001;7:340-4.
10. Bobholz J, Rao S. Cognitive dysfunction in multiple sclerosis: a review of recent developments. Cur Opin Neurol 2003;16:283-8.

11. Freeman JA. Improving mobility and functional independence in persons with multiple sclerosis. J Neurol 2001;248:255-9.

12. Finlayson M, van Denend T, Hudson E. Aging with multiple sclerosis. J Neurosci Nurs 2004;36:245-51, 259.

13. Stern M, Sorkin L, Milton K, et al. Aging with multiple sclerosis. Phys Med Rehab Clin N Amer 2010;21:403-17.

14. Klaren R, Motl RW, Dlugonski D, et al. Objectively quantified physical activity in persons with multiple sclerosis. Int J MS Care 2013;94:2342-8.

15. Keysor JJ. Does late-life physical activity or exercise prevent or minimize disablement? A critical review of scientific evidence. Prev Med 2003;25:129-36

16. Latimer-Cheung AE, Pilutti LA, Hicks AL, et al. Effects of exercise training on fitness, mobility, fatigue, and health related quality of life among adults with multiple sclerosis: a systematic review to inform guideline development. Arch Phys Med Rehabil 2013;94:1800-28.

17. Motl RW, Pilutti LA. The benefits of exercise training in multiple sclerosis. Nat Rev Neurol 2012;8:487-97.

18. Dalgas U, Stenager E. Exercise and disease progression in multiple sclerosis: can exercise slow down the progression of multiple sclerosis? Ther Adv Neurol Disord 2012;5:81-95.

19. Dalgas U, Stenager E, Ingemann-Hansen T. Multiple sclerosis and physical exercise: recommendations for the application of resistanceendurance- and combined training. Mult Scler 2008;14:35-53.

20. Oken BS, Kishiyama S, Zajdel D, et al. Randomized controlled trial of yoga and exercise in multiple sclerosis. Neurol 2004;62:2058-64.

21. Rietberg MB, Brooks D, Uitdehaag BMJ, et al. Exercise therapy for multiple sclerosis. Cochrane Database Syst Rev 2005;(1):CD003980.

22. Glasgow RE, Vogt TM, Boles SM. Evaluating the public health impact of health promotion interventions: the RE-AIM framework. $A m$ $J$ Public Health 1999;89:1322-7.

23. Kaczanowska A. Fitness DVD production in the US. IBISWorld Industry Report 2012; OD5356.

24. McAuley E, Wójcicki TR, Gothe N, et al. Effects of a DVD-delivered exercise intervention on physical function in older adults. J Gerontol Med Sci 2013;68:1076-82.

25. Guralnik JM, Simonsick EM, Ferrucci L, et al. A short physical performance battery assessing lower extremity function: association with self-reported disability and prediction of mortality and nursing home admission. J Gerontol 1994;49:M85-94.

26. Kurtzke JF. Rating neurologic impairment in multiple sclerosis: an expanded disability status scale (EDSS). Neurology 1983;33:1444-52.

27. de Jager CA, Budge MM, Clarke R. Utility of TICS-M for the assessment of cognitive function in older adults. Int $J$ Geriatr Psychiatry 2003;18:318-24.

28. Rikli RE, Jones CJ. Senior fitness test manual. Champaign, IL: Human Kinetics, 1999.

29. Cutter GR, Baier ML, Rudick RA, et al. Development of a multiple sclerosis functional composite as a clinical trial outcome measure. Brain 1999;122:871-82.

30. Bohannon RW. Test-retest reliability of hand-held dynamometry during a single session of strength assessment. Phys Ther 1986;66:206-9.

31. Bohannon RW, Larkin PA, Cook AC, et al. Decrease in timed balance test scores with aging. Phys Ther 1984;64:1067-70.

32. Ford HL, Gerry E, Tennant A, et al. Developing a disease specific quality of life measure for people with multiple sclerosis. Clin Rehabil 2001;15:247-58.

33. Hobart J, Lamping D, Fitzpatrick R, et al. The Multiple Sclerosis Impact Scale (MSIS-29): a new patient-based outcome measure. Brain 2001;124:962-73.

34. Diener E, Emmons RA, Larsen RJ, et al. The satisfaction with life scale. J Pers Asses 1985;49:71-5

35. Benedict RHB, Amato MP, Boringa J, et al. Brief International Cognitive Assessment for MS (BICAMS): international standards for validation. BMC Neuro 2012;12:55.

36. Rovniak LS, Anderson ES, Winett RA, et al. Social determinants of physical activity in young adults: a prospective structural equation analysis. Ann Behav Med 2002;24:149-56.

37. McAuley E. Self-efficacy and the maintenance of exercise participation in older adults. J Behav Med 1993;16:103-13.

38. Krupp LB, LaRocca NG, Muir-Nash J, et al. The fatigue severity scale. Application to patients with multiple sclerosis and systemic lupus erythematosus. Arch Neurol 1989;46:1121-3.

39. Zelinski EM, Gilewski MJ. A 10-item Rasch modeled memory self-efficacy scale. Aging Ment Health 2004;8:293-306.

40. McAuley E, Mihalko SL, Rosengren K. Self-efficacy and balance correlates of fear of falling in the elderly. J Aging Phys Activ 1997;5:329-40. 
41. Godin G, Shephard RJ. A simple method to assess exercise behavior in the community. Can J Appl Sport Sci 1985; $10: 141-6$.

42. Zigmond AS, Snaith RP. The hospital anxiety and depression scale. Acta Psych Scand 1983;67:361-70.

43. McAuley E, Konopack JF, Motl RW, et al. Measuring disability and function in older women: psychometric properties of the late-life function and disability instrument. J Gerontol A Biol Sci Med Sci 2005;60:901-9.

44. McAuley $\mathrm{E}$, Hall $\mathrm{K}$, Motl $\mathrm{R}$, et al. Trajectory of declines in physical activity in community-dwelling older women: social cognitive influences. J Gerontol B Psychol Sci Soc Sci 2009;64B:543-50.

45. Wójcicki TR, White SW, McAuley E. Assessing outcome expectations in older adults: the multidimensional outcome expectations for exercise scale. J Gerontol B Psychol Sci Soc Sci 2009;64B:33-40.

46. McGuigan $\mathrm{C}$, Hutchinson $\mathrm{M}$. Confirming the validity and responsiveness of the Multiple Sclerosis Walking Scale-12 (MSWS-12). Neurol 2004;62:2103-5.

47. Fox KR, Corbin CB. The physical self-perception profile: development and preliminary validation. J Sport Exerc Psychol 1989;11:408-30.
48. Melzack R. The short-form McGill pain questionnaire. Pain 1987;30:191-7.

49. McAuley E, Blissmer B, Katula J, et al. Exercise environment, self-efficacy, and affective responses to acute exercise in older adults. Psychol Health 2002;15:341-57.

50. Marshall AL, Miller YD, Burton NW, et al. Measuring total and domain-specific sitting: a study of reliability and validity. Med Sci Sports Exerc 2010;42:1094-102.

51. Russell D, Peplau LA, Cutrona CE. The revised UCLA loneliness scale: concurrent and discriminant validity evidence. J Pers Soc Psychol 1980;39:472-80.

52. Riazi A, Hobart JC, Lamping DL, et al. Multiple Sclerosis Impact Scale (MSIS-29): reliability and validity in hospital based samples. J Neurol Neurosurg Psychiatry 2002;73:701-4.

53. Pavot W, Diener E. Review of the satisfaction with life scale. Psych Assess 1993;5:164-72.

54. Creswell JW. Qualitative inquiry and research design: choosing among five approaches. Los Angeles, CA: Sage, 2012.

55. Sandroff BM, Motl RW, Suh Y. Accelerometer output and its association with energy expenditure in persons with multiple sclerosis. J Rehabil Res Dev 2012;49:467-75. 